\title{
Method of statistical data processing safety ecological monitoring combined heat and power station in the megalopolis territory
}

\author{
Valeriy Telichenko ${ }^{1, *}$, Michail Slesarev ${ }^{1}$, Tatiana Kuzovkina ${ }^{1}$ \\ ${ }^{1}$ Moscow State University of Civil Engineering, Institute of Hydraulic Engineering and \\ Power Plant Construction, Department of Construction of Thermal and Atomic Power \\ Stations, EDP Sciences, Yaroslavskoye sh. 26, 129337 Moscow, Russia
}

\begin{abstract}
The first developed method allowed to determine the combined effects of emissions of pollutants into the atmospheric air in the city by combined heat and power stations group, as well as to assess the interference impact of combined heat and power station ion the child population in different districts of Moscow. It has been proven emissions of pollutants by combined heat and power station interference are distributed on the territory of the city and does not equally affect the disease incidence of children in different administrative districts with emissions of each of the combined heat and power stations individually and do not exceed maximum allowable concentrations.
\end{abstract}

\section{Introduction}

Analyzed the possibility of known quality assessment methods presented in the list of references under the numbers [1 - 3] and [4], which, as it turns out, are inappropriate for environmental impact assessment of stationary objects energy. The individual characteristics of the emissions of pollutants by objects energy in these methods cannot be regarded. Were also reviewed the methodology of ecological assessment of the quality of the territories represented in the bibliography numbered [5 - 8] and [9], which were also inappropriate for environmental impact assessment of stationary objects on quality of the environment.

Therefore, the authors developed a new method of environmental assessment and evaluation of the quality of the territory based on correlation dependencies between emissions of pollutants from objects energy, air condition, and disease incidence of the population.

The methodological basis of the investigational study was mathematical statistics methods, correlation data analysis, information modeling, methods of assessment ecological safety in the construction industry and municipal services.

\footnotetext{
* Corresponding author: President@mgsu.ru
} 
The accuracy of the study results justified by applying adequate scientific practice research and analytical apparatus, using data obtained from official records of urban medical services and statistical data published by city services environmental monitoring, as well as approbation of results. When making an assessment of ecological safety of municipal services approved applied scientific and theoretical positions. Upon receipt of new data and the results used the standard number of measurements required to get results with a margin of error of no more than $5 \%$ when the probability belief of 0.95 .

Environmental assessment of impact by energy objects in the work presented for example combined heat and power stations in Moscow.

\section{Main part}

Correlation analysis of data in environmental assessment of combined heat and power stations of the city of Moscow has allowed to determine the contribution of emissions from combined heat and power stations in air pollution, and also revealed the relationship with disease incidence of children living near the location of stationary objects energy. Source data taken from official sources in the form of «2-TP (air)» for the period from 2006 to 2013 years. Environmental data for analysis taken from atmospheric air pollution monitoring stations in the vicinity of each of combined heat and power station, located on the territory of the city of Moscow for a similar period of time. Correlation analysis of data was carried out using paired correlation between emissions of pollutants from stationary objects of power and disease incidence of children of Moscow aged 0 to 14 years. Study period from year 2005 to 2011 biennium. The results of correlation analysis are divided into 14 stationary objects energy, 4 types of disease incidence and 6 types of pollutants.

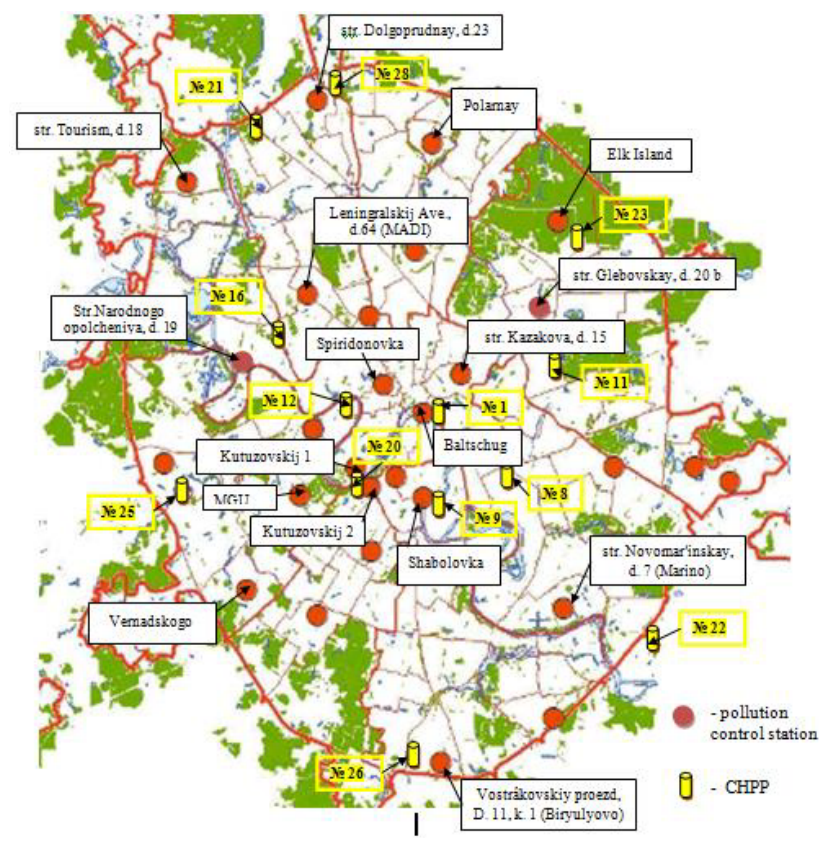

Fig. 1. Location of the stations monitors pollution and emissions of pollutants and locations of combined heat and power stations on the territory of the city of Moscow.

Assessment method of combined heat and power stations effects on environmental quality using correlation analysis data of ecological monitoring is to contained the 
correlation analysis of pollutant emissions each combined heat and power stations with disease incidence of the population in each of the districts: $f\left(p_{i} ; z_{1}\right) ; f\left(p_{i} ; z_{2}\right) \ldots f\left(p_{i} ; z_{n}\right)$.

Graphic display method for assessing the impact of combined heat and power stations on the environmental quality using correlation analysis presented in Figure 1, where $\mathrm{P}_{1} \ldots \mathrm{P}_{\mathrm{i}}$ - sources of air pollution; $Z_{1} \ldots Z_{n}$ - disease incidence of the child population in administrative districts of the city.

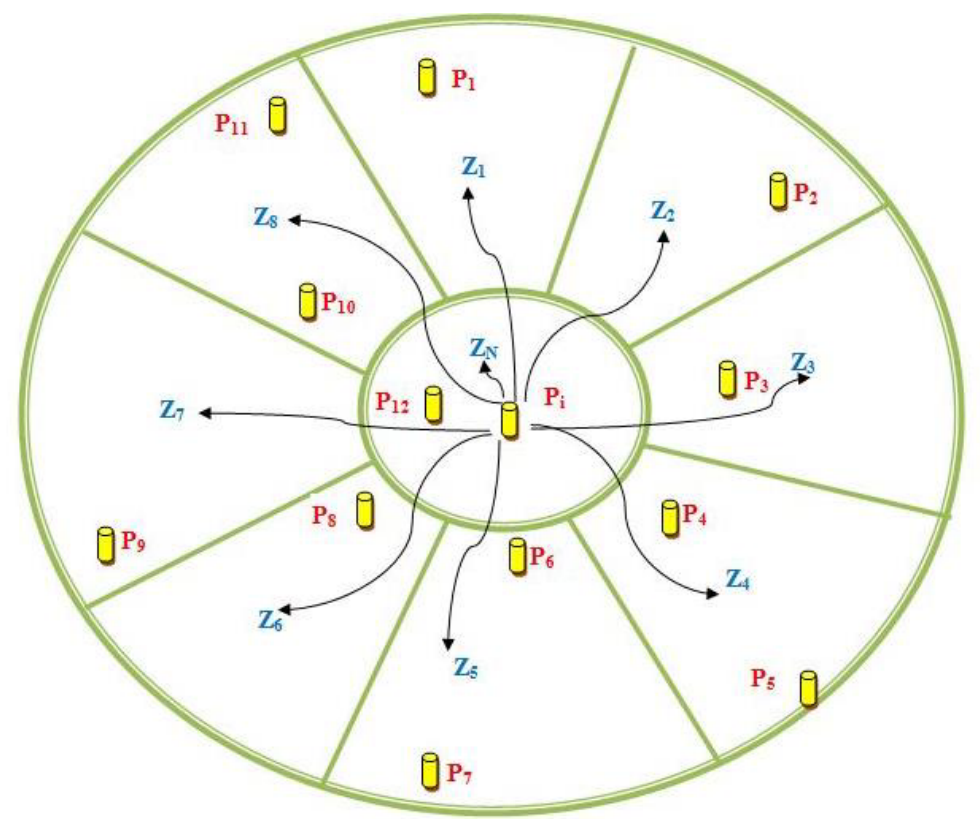

Fig. 2. Scheme of correlation analysis of pollutant emissions combined heat and power stations and disease incidence of child population.

Analysis of correlation of dependencies of pollutant emissions from combined heat and power stations and air condition was conducted according to the scheme shown in Figure 3.

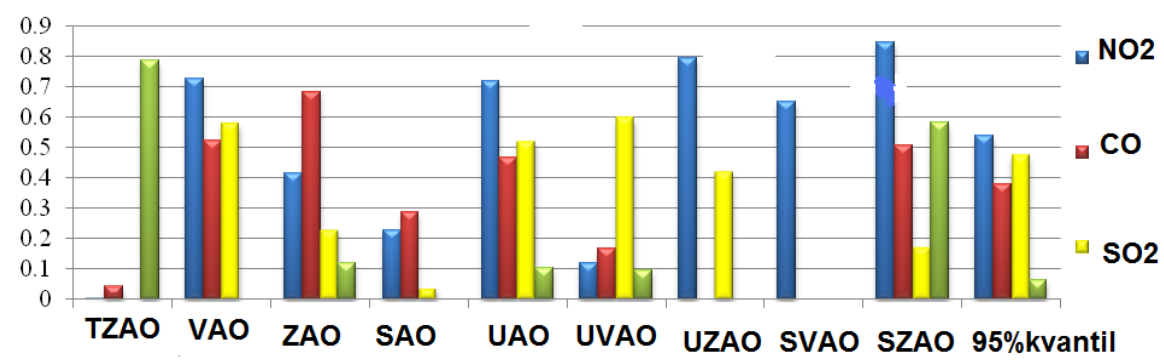

Fig. 3. The magnitude of the correlation between emissions of pollutants the combined heat and power stations and the air condition of the city of Moscow.

Analysis of data on the diseases incidence of upper respiratory tract organs (AIDP) was conducted on emissions from combined heat and power stations to nitrogen dioxide and solids. Density (power) correlation between values of pollutant emissions from combined heat and power stations and diseases incidence of the organs of the upper respiratory tract of children in Moscow are shown in Table 1. 
Table 1. Interference emissions of pollutants combined heat and power stations (CHPP) and the correlation with the disease incidence of upper respiratory organs of the child population in administrative districts of Moscow.

Thus was developed and tested method that includes approach «each object energy with each subject territory». This method allowed to determine interference picture of inter

\begin{tabular}{|c|c|c|c|c|c|c|c|c|c|c|c|c|}
\hline $\begin{array}{l}\text { Name } \\
\text { title }\end{array}$ & $\begin{array}{c}\text { Pollu- } \\
\text { tion }\end{array}$ & TZAO & VAO & ZAO & SAO & UZAO & A & ZAO & UAO & UVAO & $\begin{array}{l}\text { Arithmetic } \\
\text { middling }\end{array}$ & $\begin{array}{c}95 \% \\
\text { quantile }\end{array}$ \\
\hline \multirow{2}{*}{ CHPP-1 } & $\mathrm{NO} 2$ & 0.993 & 0.335 & 0.953 & 0.831 & 0.991 & 0.831 & 0.902 & 0.713 & 0.376 & 0.769 & 0.415 \\
\hline & Solids & 0.984 & 0.040 & 0.819 & 0.627 & 0.906 & 0.627 & 0.733 & 0.472 & 0.083 & 0.588 & 0.525 \\
\hline \multirow{2}{*}{ CHPP-8 } & $\mathrm{NO} 2$ & 0.755 & 0.806 & 0.960 & 1.000 & 0.896 & 1.000 & 0.989 & 0.983 & 0.831 & 0.913 & 0.834 \\
\hline & Solids & 1.000 & 0.213 & 0.906 & 0.753 & 0.966 & 0.754 & 0.841 & 0.619 & 0.256 & 0.701 & 0.292 \\
\hline \multirow{2}{*}{ CHPP-9 } & $\mathrm{NO} 2$ & 0.700 & 0.851 & 0.934 & 0.996 & 0.857 & 0.996 & 0.974 & 0.995 & 0.873 & 0.908 & 0.831 \\
\hline & Solids & 0.987 & 0.375 & 0.964 & 0.854 & 0.996 & 0.854 & 0.920 & 0.742 & 0.415 & 0.790 & 0.455 \\
\hline \multirow{2}{*}{$\begin{array}{c}\text { CHPP- } \\
11\end{array}$} & $\mathrm{NO} 2$ & 0.981 & 0.025 & 0.810 & 0.616 & 0.900 & 0.616 & 0.723 & 0.459 & 0.068 & 0.578 & 0.513 \\
\hline & Solids & 0.403 & 0.804 & 0.015 & 0.292 & 0.159 & 0.292 & 0.151 & 0.464 & 0.777 & 0.373 & 0.196 \\
\hline \multirow{2}{*}{$\begin{array}{c}\text { CHPP- } \\
12\end{array}$} & $\mathrm{NO} 2$ & 0.918 & 0.589 & 1.000 & 0.955 & 0.988 & 0.955 & 0.988 & 0.883 & 0.624 & 0.878 & 0.620 \\
\hline & Solids & 0.347 & 0.991 & 0.707 & 0.875 & 0.573 & 0.875 & 0.796 & 0.950 & 0.996 & 0.790 & 0.448 \\
\hline \multirow{2}{*}{$\begin{array}{c}\text { CHPP- } \\
16\end{array}$} & NO2 & 0.978 & 0.013 & 0.803 & 0.606 & 0.894 & 0.606 & 0.715 & 0.448 & 0.056 & 0.569 & 0.502 \\
\hline & Solids & 0.984 & 0.392 & 0.969 & 0.863 & 0.997 & 0.863 & 0.927 & 0.755 & 0.432 & 0.798 & 0.472 \\
\hline \multirow{2}{*}{$\begin{array}{c}\text { CHPP- } \\
20\end{array}$} & $\mathrm{NO} 2$ & 0.970 & 0.024 & 0.780 & 0.576 & 0.877 & 0.576 & 0.688 & 0.415 & 0.020 & 0.547 & 0.470 \\
\hline & Solids & 0.124 & 0.995 & 0.527 & 0.742 & 0.371 & 0.742 & 0.637 & 0.853 & 0.990 & 0.665 & 0.359 \\
\hline \multirow{2}{*}{$\begin{array}{c}\text { CHPP- } \\
21\end{array}$} & $\mathrm{NO} 2$ & 0.804 & 0.403 & 0.483 & 0.222 & 0.628 & 0.222 & 0.360 & 0.037 & 0.363 & 0.391 & 0.227 \\
\hline & Solids & 0.311 & 0.996 & 0.679 & 0.856 & 0.540 & 0.856 & 0.772 & 0.937 & 0.999 & 0.772 & 0.553 \\
\hline \multirow{2}{*}{$\begin{array}{c}\text { CHPP- } \\
22\end{array}$} & $\mathrm{NO} 2$ & 0.983 & 0.39 & 0.970 & 0.865 & 0.998 & 0.865 & 0.929 & 0.757 & 0.436 & 0.800 & 0.475 \\
\hline & Solids & 0.959 & 0.065 & 0.754 & 0.543 & 0.857 & 0.543 & 0.658 & 0.377 & 0.021 & 0.531 & 0.434 \\
\hline \multirow{2}{*}{$\begin{array}{c}\text { CHPP- } \\
23\end{array}$} & $\mathrm{NO} 2$ & 0.953 & 0.086 & 0.740 & 0.525 & 0.846 & 0.525 & 0.642 & 0.358 & 0.042 & 0.524 & 0.415 \\
\hline & Solids & 1.000 & 0.207 & 0.904 & 0.749 & 0.964 & 0.750 & 0.837 & 0.614 & 0.250 & 0.697 & 0.285 \\
\hline \multirow{2}{*}{$\begin{array}{c}\text { CHPP- } \\
25\end{array}$} & $\mathrm{NO} 2$ & 0.796 & 0.416 & 0.455 & 0.208 & 0.617 & 0.208 & 0.347 & 0.023 & 0.376 & 0.383 & 0.217 \\
\hline & Solids & 0.719 & 0.836 & 0.943 & 0.998 & 0.871 & 0.998 & 0.980 & 0.992 & 0.859 & 0.911 & 0.835 \\
\hline \multirow{2}{*}{$\begin{array}{c}\text { CHPP- } \\
26\end{array}$} & $\mathrm{NO} 2$ & 0.976 & 0.002 & 0.796 & 0.598 & 0.890 & 0.598 & 0.707 & 0.439 & 0.046 & 0.561 & 0.493 \\
\hline & Solids & 0.719 & 0.836 & 0.943 & 0.998 & 0.871 & 0.998 & 0.980 & 0.992 & 0.859 & 0.911 & 0.835 \\
\hline \multirow{2}{*}{$\begin{array}{c}\text { CHPP- } \\
28\end{array}$} & $\mathrm{NO} 2$ & 0.224 & 1.000 & 0.610 & 0.806 & 0.463 & 0.806 & 0.712 & 0.902 & 0.999 & 0.725 & 0.472 \\
\hline & Solids & 0.000 & 0.000 & 0.000 & 0.000 & 0.000 & 0.000 & 0.000 & 0.000 & 0.000 & - & - \\
\hline
\end{tabular}

influence pollutant emissions from combined heat and power stations, based on the air condition impact on disease incidence of child population in administrative districts of Moscow. 


\section{Conclusions}

The developed method allowed to determine the combined effects of combined heat power station group emissions on air condition in the city, as well as to assess the interference effect of combined heat and power plants on the child population in different districts of Moscow.

The dependence of the emission of pollutants from combined heat and power stations and air condition is a linear function for emissions of nitrogen dioxide and carbon monoxide, the emissions of sulphur dioxide, solid particles is a nonlinear function.

Proven that data correlation coefficients of pollutant emissions from combined heat and power stations and air condition depending on the type of substance: nitrogen dioxide 0.537; sulphur dioxide - 0.039; carbon monoxide - 0.378; solid particles -0.063 .

It has been proven that emissions from combined heat and power stations interference are distributed on the territory of the city and have an impact on the disease incidence of child population irregularly. Emissions of each of the combined heat and power stations alone not exceeding maximum permissible concentrations (MPC), but the overall impact from several combined heat and power stations interference is obtained and significantly increases the disease incidence of children locally of the city.

\section{References}

1. Gost R ISO/TS 21667-2009, Computerization of health. Conceptual model of health indicators (Standartinform, Moscow, 2010)

2. 2.1.10.1920-04. Guidelines for the assessment of risk to human health when exposed to chemicals polluting in the environment (Moscow, 2004)

3. Methodology of evaluation criteria of ecological situation of the territories to identify environmental emergency zones and ecological disaster zones (Moscow, 1999)

4. OND-86 technique for calculating concentrations in ambient air of harmful substances contained in the emissions (Moscow, 1986).

5. G.A Kachaev, Methods of evaluating the ecological territory State on topographic maps: extended abstract of Cand. Sci. (Moscow, 2011)

6. G.E. Asylbekova, Estimation of ecological state of Pavlodar urban ecosystems using plant sites: extended abstract of Cand. Sci. (Novosibirsk, 2010)

7. S.N. Kirillov, J.S. Polovinkina, Vestnik of Volgograd State. University, part 3, Econ. Ecol. 1(18), 239-245 (2011)

8. M.V. Lewinsky, Ecological-genetic environmental assessment and the health of the population in some industrial centers of the Republic of Moldova: extended abstract of Cand. Sci. (Voronezh, 2008)

9. Z.M. Mustafayeva, Use of GOSTS, environmental pathology and stability of plant development as biorecognition parameters of quality environmental: extended abstract of Cand. Sci. (Kaluga, 2005) 